and only moderate agreement for neglect and negligence classifications. Discordance is related to missing or unknown information and the interpretation of identified risk factors. Due to these limitations, standardised death scene investigations for all infant and child deaths are invaluable and implementing a systematic decision tree metric is necessary to produce more reliable estimates.

\section{EFFECTIVE METHODS FOR IDENTIFYING CHILD MALTREATMENT WITHIN THE FAMILY - NATIONAL CLINICAL GUIDELINE}

1,2Eija Paavilainen, ${ }^{1,3}$ Aune Flinck. 'University of Tampere, Finland; ${ }^{2}$ Etelä-Pohjanmaa
Hospital District, Finland; ${ }^{3}$ National Institute of Health and Welfare, Finland

10.1136/injuryprev-2016-042156.289

Background Child maltreatment (physical or psychological abuse or neglect of young people, under 18 years of age) is a sensitive and complex issue both in terms of clinical practice and research. It is a matter of concern for both child protective services and health services and in all services dealing with children, and families with children.

Objective of our systematic review was to synthesise the best available evidence regarding the effectiveness of methods in identifying child maltreatment. The National Clinical Guideline (www.hotus.fi) was updated in 2015, based on the systematic review.

Results Risk factors concerning the child, parents ad the family situation are presented. Methods for the examination, identification, and evaluation of rib fractures, abdominal injuries, bruises, and burns were found. Screening tools have been developed especially for emergency care and risk assessment. Evidence of the need to develop multiprofessional practice services (including policy and organisational development) was found. Educating staff concerning child maltreatment issues was found to be effective. Guidelines based on this evidence are presented.

Conclusions Methods for identification are often insufficient. However, several useful methods and tools were found. Professionals need continuous training, clinical supervision, attitude change at the individual level, and coherent tools to identify risks and cases of maltreatment and family violence in general. From the effectiveness point of view, research has been made to some degree so far.

\section{Pedestrian and Cyclists Safety}

\section{Parallel Tue 2.3}

\section{DEVELOPMENT AND EVALUATION OF A SOCIAL MARKETING APPROACH TO REDUCE PEDESTRIAN INJURY RISK}

Andrea Gielen, Maryanne Bailey, Keshia Pollack, Eileen McDonald, Jim Williams. Johns Hopkins Centre for Injury Research and Policy, USA

\subsection{6/injuryprev-2016-042156.290}

Background Pedestrian injuries continue to be an intractable global public health. Engineering changes and enforcing traffic laws have considerable evidence supporting their effectiveness. Also important but less well understood is how to influence pedestrian and driver behaviour through educational campaigns.
Our purpose is to describe how we developed, implemented and evaluated a social marketing campaign to address this gap.

Methods The site was an urban academic medical centre campus where large numbers of students, staff, patients, and visitors drive and walk daily. Formative research included focus groups with the target audience. A two-phase, six-month campaign targeted both drivers and pedestrians, and was based on social marketing concepts of product, price, promotion, and place. Evaluation included baseline, mid-term, and follow-up online surveys of campus and community respondents. We analysed the proportion who reported: 1) exposure to the campaign and their reactions to it; and 2) driving and street crossing behaviours.

Results Online survey sample sizes were 3,928 at baseline, 2,705 at mid-term, and 3,017 at follow-up. At mid-term 82\% reported having seen campaign materials and at follow-up this $\%$ was 78 . At both time points the majority of respondents $(\geq 70 \%)$ rated the campaign positively. At follow-up the proportion reporting they often looked both ways before crossing an intersection was $94.5 \%$ for those reporting exposure to the campaign and $88.1 \%$ for those reporting no exposure to the campaign. The proportion reporting they often drove slowly through intersections to look for pedestrians was $50 \%$ for those reporting exposure to the campaign and $42 \%$ for those reporting no exposure to the campaign.

Conclusions Few pedestrian safety campaigns are systematically planned and evaluated. This work (which includes a free dissemination guide) provides a roadmap to developing such interventions, and results show promise for enhancing individuals' safety.

\section{PEDESTRIAN ADOLESCENTS: MOBILITY AND SAFETY AT SECONDARY SCHOOL IN FRANCE}

${ }^{1}$ Marie-Axelle Granié, ${ }^{1}$ Thierry Brenac, ${ }^{2}$ Florence Huguenin-Richard, ${ }^{3}$ Thierry Saint-Gérand, ${ }^{3}$ Mohand Medjkane, ${ }^{1}$ Elisa Maître, ${ }^{1}$ Jean-François Peytavin, ${ }^{4}$ Florent Varet, ${ }^{1}$ Cécile Coquelet. 'IFSTTAR-TS2-LMA, France; ' ${ }^{3}$ nniversity of Paris Sorbonne, France; ${ }^{3}$ University of Caen, France; ${ }^{4}$ Aix-Marseille University, France

\subsection{6/injuryprev-2016-042156.291}

Background The road crash peak among children is around 1112 years-old in France, as in many industrialised countries, at the time of entry in secondary school. The reasons why this vulnerability increases while the skills involved should have improved are not clear.

By linking two fields of analysis of road safety (fine spatial analysis of crashes and depth analysis of behaviours and psychosocial factors), our project aimed to finely identify the mobility and pedestrian accident involvement of the 10-15 years old and specify geographical, psychological and sociological determinants of both variables.

Methods and results A study of accident processes among pedestrians aged 10-15 years over France for the period 2002-2011 was conducted, based on the national accident file and on a sample of accident police reports. It was completed in the field of study of the Lille region (France) by the spatial analysis of local accident data (including the identification of accident scenarios) and the mobility of 10-15 years, using data from the 2006 household travel survey.

Two field surveys were then conducted. A first survey among 2500 junior high school students has identified the fine mobility practices and their socio-spatial determinants. It also explored the demographic and psychological variables (age, gender roles, perceptions of social norms, risks, rules, level of supervision) explaining the reported pedestrian risky behaviours. A second 